\title{
Proceeding
}

Supplementary Issue: Autumn Conferences of Sports Science. Costa Blanca Sports Science Events, 18-19 December 2020. Alicante, Spain.

\section{Dependence of objectivity in basketball game officiating on the number of referees}

\author{
PETR HRUSA $\triangle$, DAGMAR HRUSOVA \\ Department of Leisure and Tourism, Faculty of Informatics and Management, University of Hradec Kralove, \\ Czech Republic
}

\begin{abstract}
The aim was to evaluate the level of objectivity of basketball game officiating and find out, if there is a significant difference in dependence on the number of referees. The core of the study was to verify the assumption that three-person officiating (3PO) brings higher objectivity in basketball game officiating, compared to two-person officiating (2PO). The problem was solved by empirical, descriptive and causal research with quantitative and qualitative analysis. 60 selected games (30 2PO and 30 3PO) of the top Czech Basketball Federation (CBF) competition were evaluated. The level of objectivity was evaluated by means of these indicators: number of foul calls, number of referees' mistakes, index of mistakes, and number of offball fouls. The statistical significance of the difference was evaluated in Chi-square test ( $X^{2}$, a .05). Qualitative analysis was based on the minimum required criteria according to expert opinions of top league CBF referees $(n=26)$. The significant difference in the number of foul calls was not confirmed. The results showed significant difference in decrease of number of referees' mistakes and index of mistakes and in increase of number of off-ball fouls. The findings support the idea of 3PO system to be efficient.

Keywords: Three-person officiating; Referees' mistakes; Fouls; Objectivity; Decision-making.

Cite this article as:

Hrusa, P., \& Hrusova, D. (2021). Dependence of objectivity in basketball game officiating on the number of referees. Journal of Human Sport and Exercise, 16(2proc), S601-S609. doi:https://doi.org/10.14198/jhse.2021.16.Proc2.45

Corresponding author. Department of Leisure and Tourism, Faculty of Informatics and Management, University of Hradec Kralove, Rokitanskeho 62, 50003 Hradec Kralove, Czech Republic. https://orcid.org/0000-0001-5560-2963

E-mail: petr.hrusa@uhk.cz

Abstract submitted to: Autumn Conferences of Sports Science. Costa Blanca Sports Science Events, 18-19 December 2020. Alicante, Spain.

JOURNAL OF HUMAN SPORT \& EXERCISE ISSN 1988-5202

(c) Faculty of Education. University of Alicante

doi:10.14198/jhse.2021.16.Proc2.45
\end{abstract}




\section{INTRODUCTION}

Basketball game is developing very fast because the players are taller, stronger and more athletic. The International Basketball Federation responds to this situation by issuing new interpretations of the rules approximately every 2 years, slightly modifying the official basketball rules every 4 years. With the development of power and speed abilities of modern basketball players, the International Basketball Federation has decided that the highest national competitions shall be officiated by three referees and introduced the so-called 3PO (three-person officiating) mechanics. Change in the number of referees from 2 to 3 brings changes in referees' teamwork in the game. In Czech Basketball Federation (CBF), the threereferee system, has been introduced from the season 2005/06, for the top men and league. The age limit of the referees is 53 years. For lower competitions in CBF, there is a two-referee system (the so-called 2PO, two-person officiating), with no age limit. To compare, three-referee system, with no age limit, is also used in the Euro league and in the National Basketball Association (NBA). In the system of 2 referees (Lead and Trail), there are several problem areas on the court, which, under certain conditions, might not be covered. This situation should be covered better in the system of 3 referees (Lead, Centre and Trail). Today, most of the top competitions in Europe are officiated by 3 referees, and this system is gradually being introduced into lower competitions. The research focuses on the problem how the objectivity of basketball game officiating differs between 2PO and 3PO.

\section{THEORETICAL FRAMEWORK}

Current research shows the importance and influence of the basketball referee during competition (GarciaSantos et al., 2020). Referees' decisions are expected to be fast and correct and high level of referees' objectivity is expected by all the interested parties. Recent research has reviewed (Nabli et al, 2019) that basketball refereeing puts specific demands on the referees to keep up with gameplay, in terms of physical/physiological, perceptual, and cognitive parameters. The referees are required to keep up with the energy demands and follow the game by moving in strategic positions to be able to judge players' actions (Nabli et al., 2016). Aerobic and anaerobic demands in basketball players differ according to their strategic and positional roles in the game (Pojskič at al., 2015).

Making a good decision relates to good cooperation of all referees (Smid, 2015). High demands are claimed on decision-making. One of the important aspects of decision-making profile is workmate collaboration (García Santos, 2020). Workmate collaboration is highly involved in 3PO system in basketball games. The functional coverage of the court by the referees in 3PO is depicted in Figure 1 below the description of 3PO mechanics. The referees in 3PO have their individual positions on the court (Lead, Centre, Trail), competencies, duties and responsibilities. One of the referees is nominated as the crew chief, but concerning the control of the game, all 3 referees have the same rights. In 3PO there are always 2 referees (Lead and Trail) on the side where the ball is (strong side) and 1 referee (Centre) on the side without the ball (weak side). These areas are imaginarily divided by an imaginary line from basket to basket. The referees keep changing the positions throughout all the game, via the so-called rotation. The rotation is determined by the Lead, who, when rotating, moves to the other side of the restricted area along the end line. At the same time the Trail becomes the Centre, so for a while there are 2 referees on the same level and then the original Centre becomes a Trail. The referees change their positions in dependence on the movement of the ball.

Klein (1993) explains that decision-making process involves recognizing that a game conflictive situation has occurred and then responding, based on the knowledge and experience. The referee's decision can be spontaneous, when they rely on their intuitive processing (Lamba and Ozdasli, 2015). Referees can get under 
pressure when they are expected to make correct decisions within limited time. Recent research also considers the effects that the team, player and spectators may have on referees' behaviour as an important factor in understanding how biased decisions may occur, regardless of whether they are a consequence of favouritism towards one team or not. Gencay and Aydin (2015) investigated bias and favouritism in basketball referees. The referees responded that they were affected by the players in their decisions of fouls. It was also found out (Gencay and Aydin, 2015) that the degree of being affected by factors such as players, teams and spectators varied according to the sporting experience. Anderson and Pierce (2009) examined the pattern of foul calls exhibited during 365 NCAA basketball games. Results of their analysis indicated that referees are more likely to call fouls on the team with fewer fouls, making it likely that the number of fouls will tend to even out during the game. Noecker and Roback (2012) revised and strengthened the study of Anderson and Pierce (2009). Using a logistic regression model, they determined that referees display a statistically significant tendency to even out the foul count between the two teams. On the other hand, Morgulev et al. (2018) found no evidence of favouritism granted to the home team, star players, or to highreputation teams.

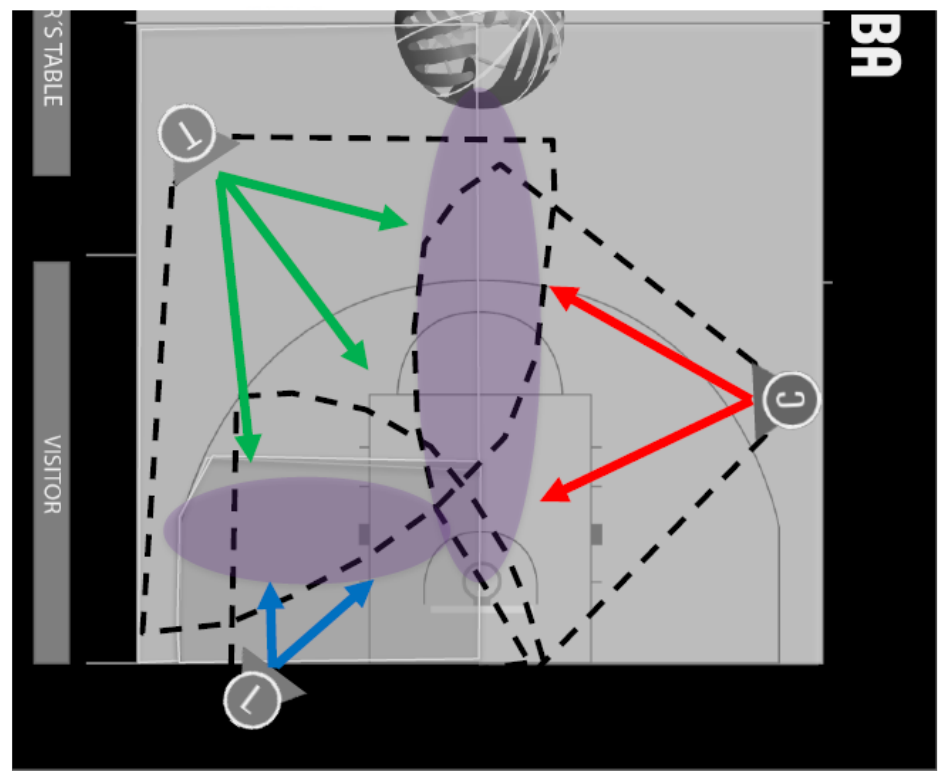

Figure 1. Functional coverage of the court in 3PO (Basketref, 2020).

The relation of players and referees can be seen as a potential source of conflict (Rainey,1992). Negative emotions can be triggered from the outside (Atkinson, 2003). The referee's decision may be perceived as incorrect and can trigger negative behaviour of players or coaches (Weinberg and Gould, 1995; Rainey et al., 1992) or pressure of spectators (Sors, et al., 2019). Aggressive reactions of coaches and players were studied as sources of acute stress among basketball referees. Difference between two-person officiating (2PO) and three-person officiating (3PO) can play a role. Positive effects of the change from 2PO to 3PO have been studied, decreasing negative expressions of basketball players' behaviour in 3PO (Hruša, 2014). The findings suggest there are individual differences in coping strategies between intermediate and elite basketball referees (Kaissidis 1997).

A potential possibility of making a mistake can be stressful for referees. Players, coaches and spectators expect perfection, with no mistakes and consistency from referee to referee and from game to game (FIBA, 2016). The decisions of referees with high anxiety might be more easily influenced by external factors, like 
crowd noise (Sors et al., 2019). The referees should understand that they cannot control the game unless they control themselves (Rigas, 2008). Research focused on officiating has consistently shown that mistakes and bias are inevitable, due to limitations in perceptual function (Sanabria et al. 1998). At all levels of sport, the quality of the officials' decision-making process can determine the difference between winning and losing (Hudson, 2006).

\section{METHODS}

\section{Aim and hypothesis}

The aim was to evaluate the level of objectivity in basketball game officiating and find out, if there is a significant difference in objectivity of game officiating in dependence on the number of referees. The core of the study was to verify the hypothesis that the three-referee system (three-person officiating - 3PO) brings higher objectivity in game officiating, compared to the two-referee system (two-person officiating - 2PO). The level of objectivity was evaluated by means of 4 variables (foul calls, referees' mistakes, index of mistakes, and off-ball fouls) and their indicators in partial hypotheses:

H1.1 Higher level of objectivity was assumed in 3PO games compared to 2PO games in number of foul calls. The total number of personal fouls of both teams was expected to be higher in $3 \mathrm{PO}$.

H1.2 Higher level of objectivity was assumed in 3PO games compared to 2PO games in referees' mistakes. The total number of all the referees' mistakes was expected to be lower in 3PO.

H1.3 Higher level of objectivity was assumed in 3PO games compared to 2PO games in index of mistakes. The ratio of the number of referees' mistakes to the number of foul calls was expected to be lower in $3 \mathrm{PO}$. $\mathrm{H1}$.4 Higher level of objectivity was assumed in 3PO games compared to 2PO games in the number of offball fouls. The total number of fouls on a player who is not controlling the ball - not holding, dribbling or shooting, was expected to be higher in 3PO.

\section{Research design}

The problem was solved by empirical, descriptive and causal research with quantitative and qualitative analysis. 3 experts (2 top basketball referees, 1 commissioner) observed and evaluated the total of 60 selected games (30 games in 2PO, 30 games in 3PO system) of the top Czech Basketball Federation (CBF) competition. A pilot study was carried out before the main research. The main task of the pilot study was to select and verify appropriate method - direct or indirect observation. 3 independent observers (2 referees, 1 commissioner) evaluated 5 selected basketball games (top Czech league) in direct observation, indirect observation and repeated indirect observation (games recorded on DVDs, available via the database of Czech Basketball Federation), in the pilot study. Based on the results of od the pilot study, the method of indirect repeated observation was selected. It had sufficient validity to direct observation (repeated assessment of the indicators) and also had the advantage of more accurate assessment of the observed phenomena. Objectivity was calculated, based on the Spearman correlation coefficient (agreement of at least 2 out of 3 independent observers, for all the indicators listed above). Reliability was calculated, based on the correlation of the direct and repeated indirect observation after 30 days.

\section{Data analysis}

Chi-square test was used in quantitative analysis to evaluate statistical significance of the difference $\left(X^{2}, a\right.$ .05) between 3PO games and 2PO games. In qualitative analysis the data were evaluated according to the criterion determining the minimum required difference between $2 \mathrm{PO}$ games and $3 \mathrm{PO}$ games, for all the given indicators. The qualitative criterion was based on a consensus of expert opinions of top league CBF referees $(n=26)$ and was expressed as a percentage of the difference between an average value in 2PO games and 
3PO games for each indicator. The percentage values are given in Table 3 in the chapter of Results. The criterion described a substantive difference that may affect the course of the game and provided base for comparison with statistical evidence and arguments for discussion.

\section{RESULTS}

Descriptive characteristics of the given 4 variables and their indicators (number of foul calls, number of referees' mistakes, index of mistakes, and number of off-ball fouls) are presented below, in the overviews of all the observed games (30 2PO games and $303 \mathrm{PO}$ games).

Table 1. Descriptive statistics for $2 \mathrm{PO}$ games $(\mathrm{n}=30)$.

\begin{tabular}{lccccccc}
\hline 2PO & $\sum 2$ & Mean & Median & Min & Max & Std. Deviation & Variance \\
\hline Foul calls & 1350 & 45 & 46 & 34 & 65 & 7.22 & 57.02 \\
Referees' mistakes & 142 & 4.73 & 5 & 3 & 7 & 1.14 & 1.31 \\
Index of mistakes & 313 & 10.43 & 10 & 6 & 15 & 2.71 & 7.36 \\
Off-ball fouls & 61 & 2.03 & 2 & 0 & 5 & 1.07 & 1.14 \\
\hline
\end{tabular}

Table 2. Descriptive statistics for $3 P O$ games $(n=30)$.

\begin{tabular}{lccccccc}
\hline 3PO & $\sum 3$ & Mean & Median & Min & Max & Std. Deviation & Variance \\
\hline Foul calls & 1379 & 45.97 & 46 & 36 & 58 & 5.92 & 34 \\
Referees' mistakes & 97 & 3.2 & 3 & 1 & 6 & 1.13 & 1.27 \\
Index of mistakes & 211 & 7.03 & 6.5 & 2 & 15 & 3.05 & 9.27 \\
Off-ball fouls & 109 & 3.63 & 4 & 1 & 6 & 1.27 & 1.62 \\
\hline
\end{tabular}

When comparing the values from 2PO in Table 1 and 3PO in Table 2, there was just a small increase in the total number of foul calls in favour of 3PO. Other values show bigger difference in the remaining 3 indicators, in the sense of an expected increase in the number of off-ball fouls and decrease in the number of referees' mistakes and index of mistakes. The statistical significance of the difference and qualitative analysis based on the required minimum criteria of all the partial hypotheses are evaluated below. The results showed significant difference between 3PO (three-person officiating) and 2PO (two-person officiating) in the indicators of number of referees' mistakes, index of mistakes, and number of off-ball fouls. The significant difference in the number of foul calls was not confirmed. The results are summarized in Table 3.

Table 3. Statistical significance and qualitative analysis of the difference between $2 \mathrm{PO}$ and $3 \mathrm{PO}$ games.

\begin{tabular}{lcccccc}
\hline Indicators & $\sum_{2} / \sum_{3}$ & $X^{2}$ & $\mathrm{H}_{0} / \mathrm{H}_{\mathrm{A}}$ & $\begin{array}{c}\text { Qualitative } \\
\text { criteria }\end{array}$ & $\begin{array}{c}\text { Observed } \\
\text { difference }\end{array}$ & $\begin{array}{c}\text { Hypotheses } \\
\text { verification }\end{array}$ \\
\hline Foul calls & $1350 / 1397$ & 0.15 & $\mathrm{H}_{0}$ & $>10 \%$ & $+2.10 \%$ & NO \\
Referees' mistakes & $142 / 97$ & 4.24 & $\mathrm{H}_{\mathrm{A}}$ & $<30 \%$ & $-31.70 \%$ & YES \\
Index of mistakes & $313 / 211$ & 9.93 & $\mathrm{H}_{\mathrm{A}}$ & $<20 \%$ & $-32.60 \%$ & YES \\
Off-ball fouls & $61 / 109$ & 6.78 & $\mathrm{H}_{\mathrm{A}}$ & $>30 \%$ & $+78.80 \%$ & YES \\
\hline
\end{tabular}

\section{H1.1}

The difference found between the number of foul calls in $2 \mathrm{PO}$ and $3 \mathrm{PO}$ was not statistically significant at the selected level $\alpha .05$ and the null statistical hypothesis could not be rejected. Concerning qualitative analysis, the criterion of expert opinions agreed that the minimum required difference of $10 \%$ increase of the number of foul calls, in favour of 3PO. However, this criterion was not exceeded. The number of foul calls increased on average by only 0.97 per game $(2.1 \%)$, as shown in Table 3 . The difference was not considered significant, 
and according to the expert opinions, could not affect the course of the game. The partial hypothesis H1.1 was not confirmed.

\section{H1.2}

The difference found between the number of referees' mistakes in 2PO and 3PO was statistically significant at the selected level a .05 and the null statistical hypothesis was rejected. The relative frequency of observed referees' mistakes decreased by $31.7 \%$, which exceeded the criterion of expert opinions of the minimum required difference $(<30 \%)$. The substantive significance of the difference was confirmed in qualitative analysis. The partial hypothesis H1.2 was confirmed.

\section{H1.3}

The difference found in the index of referees' mistakes between 2PO and 3PO was statistically significant at the selected level a .05 and the null statistical hypothesis was rejected. The index, expressing the ratio of the number of referees' mistakes to the number of foul calls was expected to be lower in 3PO. The criterion of expert opinions set the minimum required difference as the decrease of at least $20 \%$, in favour of $3 \mathrm{PO}$. The value of the index decreased on average by 3.4 per game, which is a decrease of $32.6 \%$. The qualitative criterion was exceeded. The partial hypothesis $\mathrm{H} 1.3$ was confirmed.

\section{H1.4}

The difference found between the number of off-ball fouls between 2PO and 3PO was statistically significant at the selected level a .05 and the null statistical hypothesis was rejected. The number of observed off-ball fouls increased from the average value of 2.03 to 3.63 per game, which counts the increase by $78.8 \%$. The criterion of expert opinions of the minimum required difference was exceeded $(>30 \%)$. The qualitative analysis confirmed substantive significance of the difference and based on the expert opinions, could affect the course of the game. The partial hypothesis H1.4 was confirmed.

\section{DISCUSSION}

Several conditions were determined to verify the research hypothesis. Partial hypotheses were verified by means of statistical hypotheses of the significance of difference and by qualitative analysis of the data. The research strategy followed the causal method of a single difference between the research samples (30 2PO games and $303 \mathrm{PO}$ games). A sufficient amount of empirical data corresponding to the law of large numbers was obtained in the research. The large amount of data reduced the impact of intervening and disruptive variables as uncontrolled research inputs. Within the field of sport game officiating, such intervening and disruptive variables can be subjective psycho-social and objective technical-organizational influences, which are reflected during each basketball game. If the statistically and logically significant differences are consistent in the whole research sample of the selected games in the given period of time, these intervening and disruptive variables can be considered as insignificant.

The difference between the number of foul calls was surprisingly low, on average 45 foul calls in 2PO games and 46 foul calls in $3 \mathrm{PO}$ games. It was expected that the difference in averages of foul calls would be higher, after the transition from $2 \mathrm{PO}$ to $3 \mathrm{PO}$. That assumed that the referees' movement on the court in 3PO gives opportunity to see more of court. Especially in the beginning after the transition to 3PO (from the season 05/06), the problem for the referees was that in 3PO they moved around the court in different positions than they were used to in 2PO. Another problem arose with the referees having to concentrate on their movement more than expected. Therefore, most referees first had to solve their mechanics of movement on the court and then the correct selection of fouls on the court. A trend in the modern basketball development in fact 
allows the referees not to whistle a foul that does not affect the player with the ball and does not violate the RSBQ (rhythm, speed, balance and quickness). This trend could also correspond to the findings that the total number of called fouls in 2PO did not increase significantly. Concerning foul recognition, the pattern of calling fouls admits that in any sport game favouritism and bias may occur. For example, Anderson and Pierce (2009) indicated in the research in NCAA that referees are more likely to call fouls on the team with fewer fouls. On the other hand, Morgulev et al. (2018) found no evidence of favouritism granted to the home team, star players, or to high-reputation teams.

The average number of referees' mistakes reduced significantly in 3PO compared to 2PO (on average from 4.73 to 3.23 per game) According to the referees, the distribution of pressure of players, coaches, officials and spectators among 3 referees helps to cope with the pressure better and allows better decisions. The most CBF referees themselves responded in this research that they felt lower pressure and decided better in $3 \mathrm{PO}(92.3 \%)$ compared to $2 \mathrm{PO}(7.7 \%)$. More confident decisions can help the referees to cope with stress in situations of conflicts. Among such situations in basketball there are relations of referees and players, their negative reactions, especially in cases, when players or coaches may perceive the referee's decision as incorrect. Negative reactions in sport games were described by Weinberg and Gould (1995) or Rainey at al. (1992). Hruša (2014) suggests that the difference between 2PO and 3Po can play a role. Positive effects of the change of 2PO to 3PO were studied, in decreasing negative expressions of basketball players' behaviour in 3PO (Hruša, 2014). Concerning pressure and stress, Martínez-Moreno et al. (2021) reported that basketball referees experience mainly moderate level of stress and burnout, while there exist differences between the referees of top national competitions and the local-regional competitions, in addition to differences regarding the role played. The role of the referee refers to referees' teamwork in 3PO system, which was analysed by Smid (2015), from the point of view of the Centre/Lead/Trail position on the court. When evaluating the average number of referees' foul calls in the game in relation to their positions, Smid (2015) found significant difference between all positions. Concerning the referees' mistakes, the common recommendations to prevent them are: to follow the range of one's authority, always have such position to be able to see a personal foul or violation clearly, not to use "fantasy calls", cross court calls, guess calls, not to stay near end line while on the Lead position, to be able to recognize personal foul/tactical and unsportsmanlike fouls. Berezka and Chopilko (2014) found a noticeable trend of mistakes in referees' decisions, increasing as the physical distance of the referee from the situation in question increased.

The total number of off-ball fouls has increased significantly. This corresponds to better functional coverage of the court (FIBA, 2016), when in 3PO the referees can take better position on the court to see the situations better than the referees in 2PO. In particular, such situations are pick and roll and release of a player for the ball, which is held by the defender. The moving screen is very often called in this situation.

\section{CONCLUSIONS}

The results showed significant difference between 3PO (three-person officiating) and 2PO (two-person officiating) in the indicators of number of referees' mistakes, index of mistakes, and number of off-ball fouls. The significant difference in the number of foul calls was not confirmed. From a methodological point of view, we applied the general scientific methodology and research strategy of empirical research in sport science in a non-traditional subject of research - basketball officiating. The main contribution for theory and research is the confirmation of the hypothesis that in the games officiated by three referees the objectivity will be higher compared to the games officiated by two referees. The findings verified the dependence of objectivity of game officiating in basketball on the number of referees. This work is unique in its content and provides the interested officials of basketball federations supportive data about why FIBA introduced the third referee and 
why they requested this change from all the member countries. The findings support the idea that 3PO system should be applied also in lower competitions.

\section{ACKNOWLEDGEMENTS}

The paper was financially supported by the grant of Faculty of informatics and management, University of Hradec Kralove.

\section{REFERENCES}

Anderson, K., \& Pierce, D. (2009). Officiating bias: The effect of foul differential on foul calls in NCAA $\begin{array}{llll}\text { Basketball. Journal of } & \text { Sports }\end{array}$ https://doi.org/10.1080/02640410902729733

Atkinson, R. L. (2003). Psychologie. 2. ed. Praha: Portál.

Basketref Homepage. (2020). 3PO basic (part1). Retrieved from: http://www.basketref.com/documents/fiba 2016 3po/FE2016 3PObasic part1.pdf, last accessed 2021/01/15

Berezka, S. \& Chopilko, T. (2014). An investigation of individual functionality football referees $\begin{array}{llll}\text { qualifications. } \quad \text { Physical } \quad \text { Education } & \text { 8-12. }\end{array}$ https://doi.org/10.15561/20755279.2014.0602

FIBA Homepage (2016). FIBA recruitment, retention and education of referees. Retrieved from: https://vbra.basketball.net.au/wp-content/uploads/sites/4/2016/04/fiba-recruitment-retention-andeducation-of-referees1.pdf, last accessed 2020/08/29

Garcia-Santos, D., Gómez-Ruano, M. A., Vaquera, A. \& Ibáňez, S. J. (2020). Systematic review of basketball referees' performances. Int. Journal of Performance Analysis in Sport. https://doi.org/10.1080/24748668.2020.1758437

Garcia-Santos, D. \& Ibáněz, S. J. (2011). Diseño y validación de un instrument de observación para la valoración de un árbitro de baloncesto. SporTK-Revista EuroAmericana de Ciencias del deporte, 5(2), 15-26. https://doi.org/10.6018/264601

Gencay, O. \& Aydin, E. (2015). The Effects of Teams, Individual Players and Spectators on Basketball Officials' Decision-making Processes. Antrophologist, 20(3), 503-509. https://doi.org/10.1080/09720073.2015.11891754

Hruša, P. (2014). Dependence of negative expressions of basketball players' behaviour on the frequency of referees. In Milanović \& Sporiš (Eds.). Fundamental and Applied Kinesiology - Steps Forward (516-519). Croatia: Opatia.

Hudson, P. (2006). Real Time Decision Making in Sport. Retrieved from: http://members.ziggo.nl/jaap.kooman/sport/XX\%20\%20\%20\%20\%20\%20Real\%20t\%20decission \% 20making\%20in\%20sport.pdf (Retrieved on 31 May 2015).

Kaissidis Rodafinos, A., Anshel, M.H. \& Porter, A. (1997). Personal and situational factors that predict coping strategies for acute stress among basketball referees. Journal of sports science, 15(4), 427 436. https://doi.org/10.1080/026404197367218

Klein, G. (1993). A recognition-primed decision (RPD) model of rapid decision making. In: GA Klein, J Orasanu, R Calderwood, CE Zsambok (Eds.): Decision-making in Action: Models and Methods. Ablex, 138-147. Norwood, NJ.

Lamba, M. \& Ozdasli, K. (2015). Influence of social culture on decision-making manner in Turkey: An analysis with the structural equation model. Anthropologist, 19(2), 341-353. https://doi.org/10.1080/09720073.2015.11891667 
Martinez-Moreno, A., Ibáňez-Pérez, R. \& Sánchez-Roca, C. (2021). Leadership, stress and burnout among basketball referees. Journal of Human Sport Exercise, 16(1), in press. https://doi.org/10.14198/ihse.2021.161.08

Morgulev, E., Azar, O., Lidor, R., Sabag, E. \& Bar-Eli, M. (2018). Searching for Judgment Biases Among Elite Basketball Referees. Frontiers in Psychology, 9. https://doi.org/10.3389/fpsyg.2018.02637

Nabli, M., Ben Abdelkrim, N., Castagna, C., Jabri, I., Batikh, T. \& Chamari, K. (2016). Physical and physiological demands of U-19 basketball refereeing: aerobic and anaerobic demands. The Physician and Sportmedicine, 44(2), 158-163. https://doi.org/10.1080/00913847.2016.1149424

Nabli, M., Ben Abdelkrim, N., Fessi, MS., DeLang, M., Moalla, W. and \& Chamari, K. (2019). Sport science applied to basketball refereeing: a narrative review. The Physician and Sportsmedicine. 47:4, 365-374. https://doi.org/10.1080/00913847.2019.1599588

Noecker, C. \& Roback, P. (2012). New Insights on the Tendency of NCAA Basketball Officials to Even Out Foul Calls. Journal of Quantitative Analysis in Sports, 8(3). https://doi.org/10.1515/1559$\underline{0410.1402}$

Pojskic, H., Separovic, V., Uzicanin, E., Muratovic, M. \& Mackovic, S. (2015). Positional Role Differences in the Aerobic and Anaerobic Power of Elite Basketball Players. Journal of Human Kinetics, 49(1), 219-227. https://doi.org/10.1515/hukin-2015-0124

Rainey, D., Santili, N. R. \& Fallon, K. (1992). Development of Athletes' Conceptions of Sport Officials' Authority. Journal of Sport and Exercise Psychology, 14, 392-404. https://doi.org/10.1123/isep.14.4.392

Rigas, C. (2008). Personality of Referee. Wroclaw: Camp for Young Referees, unpublished.

Sanabria, J., Cenjor, C., Ma'rquez, F., Gutierrez, R., Martinez, D. \& Prados-Garcia J. (1998). Oculomotor movements. The Lancet, 351, 268. https://doi.org/10.1016/S0140-6736(05)78269-6

Smid, P. (2015). Analysis of teamwork in officiating in basketball. Journal of Human Sport Exercise, 9(1), 330-339. https://doi.org/10.14198/ihse.2015.10.Proc1.22

Sors, F., Lourido, T., Parisi, V., Santoro, I., Galmonte, A., Agostini, T. \& Murgia, M. (2019) Pressing Crowd Noise Impairs the Ability of Anxious Basketball Referees to Discriminate Fouls. Frontiers of psychology, 10. https://doi.org/10.3389/fpsyg.2019.02380

Weinberg, R. S. \& Gould, D. (1995). Foundations of Sport and Exercise. Psychology Journal of Sport Behaviour, 21(1), 113.

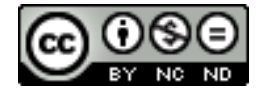

This work is licensed under a Attribution-NonCommercial-NoDerivatives 4.0 International (CC BY-NC-ND 4.0). 